\title{
Sports-related concussions: diagnosis, complications, and current management strategies
}

\author{
Jonathan G. Hobbs, MD, ${ }^{1}$ Jacob S. Young, BS, ${ }^{1}$ and Julian E. Bailes, MD² \\ 1Department of Surgery, Section of Neurosurgery, The University of Chicago Pritzker School of Medicine, Chicago; and \\ 2Department of Neurosurgery, NorthShore University HealthSystem, The University of Chicago Pritzker School of Medicine, \\ Evanston, Illinois
}

\begin{abstract}
Sports-related concussions (SRCs) are traumatic events that affect up to 3.8 million athletes per year. The initial diagnosis and management is often instituted on the field of play by coaches, athletic trainers, and team physicians. SRCs are usually transient episodes of neurological dysfunction following a traumatic impact, with most symptoms resolving in 7-10 days; however, a small percentage of patients will suffer protracted symptoms for years after the event and may develop chronic neurodegenerative disease. Rarely, SRCs are associated with complications, such as skull fractures, epidural or subdural hematomas, and edema requiring neurosurgical evaluation. Current standards of care are based on a paradigm of rest and gradual return to play, with decisions driven by subjective and objective information gleaned from a detailed history and physical examination. Advanced imaging techniques such as functional MRI, and detailed understanding of the complex pathophysiological process underlying SRCs and how they affect the athletes acutely and long-term, may change the way physicians treat athletes who suffer a concussion. It is hoped that these advances will allow a more accurate assessment of when an athlete is truly safe to return to play, decreasing the risk of secondary impact injuries, and provide avenues for therapeutic strategies targeting the complex biochemical cascade that results from a traumatic injury to the brain.
\end{abstract}

http://thejns.org/doi/abs/10.3171/2016.1.FOCUS15617

KEY WORDS concussion; mild traumatic brain injury; chronic traumatic encephalopathy; subconcussion

$\mathrm{A}$ CCORDING to the Centers for Disease Control and Prevention, sports-related concussions (SRCs) affect 1.6-3.8 million people each year in the US65 and account for 5\%-9\% of all sports-related injuries. ${ }^{40,120}$ Alarmingly, nearly $30 \%$ of these concussions occur in individuals between 5 and 19 years of age, and most result in a visit to the emergency room. These events occur in both helmeted and nonhelmeted sports alike, with concussive traumas being noted in both competition and practice settings. ${ }^{50,70}$ Among organized sports, football, wrestling, girls' soccer, boys' soccer, and girls' basketball consistently account for the majority of concussions in the US. $4,40,70,120,129$

Although almost $90 \%$ of SRCs will have a spontaneous resolution of symptoms in 7-10 days following the initial injury, ${ }^{35,79,82,90,101}$ a small percentage of athletes will experience persistent symptoms that require protracted, multidisciplinary treatment modalities. Unfortunately, it is hard to predict which athletes will suffer from extended difficulties, because symptom resolution does not indicate complete recovery from the traumatic event. To properly treat these patients, many of whom are student athletes, we must remember that there are scholastic, financial, and social implications in addition to the health concerns that make it of paramount importance that we provide optimal medical therapy. As the publicity around concussions continues to increase, it is likely that the number of patients neurosurgeons see in their practice will increase as well. This article aims to discuss the most current understanding of SRC and therapeutic strategies for neurosurgeons as well as a multidisciplinary health care team that is required to successfully ensure a safe return to play for these patients.

ABBREVIATIONS CTE = chronic traumatic encephalopathy; DHA = docosahexaenoic acid; DTI = diffusion tensor imaging; fMRI = functional MRI; GCS = Glasgow Coma Scale; ICH = intracranial hemorrhage; IL = interleukin; LOC = loss of consciousness; MRS = MR spectroscopy; mTBI = mild traumatic brain injury; PCS, PPCS = postconcussion syndrome, prolonged PCS; SCAT = Sport Concussion Assessment Tool; SIS = second-impact syndrome; SRC = sports-related concussion; TNF $\alpha=$ tumor necrosis factor- $\alpha$. 


\section{Diagnosis of a Concussion}

The diagnosis of concussion is a clinical one and relies on an understanding of the definition of "concussion," which is often used synonymously with "mild traumatic brain injury" (mTBI). However, some authorities believe that concussion actually represents a subset of mTBI and should be separated accordingly. ${ }^{46}$ Multiple definitions of concussion and mTBI exist; however, they all contain similar core characteristics.

In general, a concussion (or mTBI) is defined as a traumatically induced transient disturbance of neurological function caused by a complex pathophysiological process. ${ }^{46}$ However, there is a lack of unity among various medical bodies about what exactly constitutes this mTBI. The American Congress of Rehabilitation Medicine defines mTBI as a traumatically induced physiological disruption of brain function resulting from the head being struck or striking an object or the brain undergoing an acceleration and deceleration movement as manifested by at least one of the following: a period of loss of consciousness (LOC) up to 30 minutes; posttraumatic amnesia that does not exceed 24 hours; any period of confusion or disorientation; transient neurological abnormalities (focal neurological deficits, seizures, nonsurgical intracranial lesions); and a Glasgow Coma Scale (GCS) score of 13-15 within 30 minutes of presentation. ${ }^{17,68}$ The WHO stipulated that none of the aforementioned manifestations can be the result of intoxication (alcohol, medication, and recreational drug), systemic illness, or extracranial injuries. It should be noted that neither the American Congress of Rehabilitation Medicine nor the WHO specified a minimum duration for LOC, amnesia, or disorientation that is necessary to meet the requirements of an mTBI. The US Department of Defense adds a caveat to the definition and states that an mTBI cannot have any abnormality on conventional CT or MRI studies. ${ }^{17}$

In 2012, the 4th International Conference on Concussion in Sport (ICCS) put forth a consensus statement regarding SRCs, which provides the basis of our current diagnosis and management. According to this consensus, a concussion is defined as a complex pathophysiological process affecting the brain. A concussion is induced by biomechanical forces and includes several common features of clinical, pathological, and biomechanical injury constructs, which are used to define the nature of the concussive injury. ${ }^{95}$ A concussion results from a transmitted force to the head. It typically manifests as a rapid, transient neurological dysfunction with spontaneous resolution (although the symptoms may evolve over minutes to hours after the traumatic event). Although the concussive event may result in neuropathological changes, the symptomatology reflects a functional disturbance rather than a structural injury, which correlates with the often normal findings on conventional neuroimaging studies. The symptoms are graded and may or may not include LOC, and resolution typically follows a sequential course. However, some cases may include prolonged symptoms. ${ }^{95}$

\section{Signs and Symptoms of a Concussion}

The signs and symptoms are numerous and often non- specific. Headache is the most common symptom, followed by dizziness. An LOC is actually quite infrequent in SRCs, occurring in only $10 \%$ of cases, even though it is classically associated with mTBI., ${ }^{9,26,81,90,94,95,101}$ Amnesia and confusion are other classic symptoms of a concussion, and they are often present following a traumatic blow to the head even if there is no preceding LOC (see Table 1 for signs and symptoms of a concussion). The remaining symptoms of a concussion vary widely from patient to patient, and include multiple health care complaints, such as physical (nausea, vomiting, balance disturbance, visual changes, fatigue, photo- or phonophobia, numbness); cognitive ("foggy" mentation, difficulty concentrating, mental slowness, memory difficulty, slow response time, confusion about recent events); emotional (increased irritability, depression, anxiety, nervousness); and sleep disturbances (drowsiness, hyper- or hyposomnolence). ${ }^{46}$ These nonspecific symptoms are commonly seen in other medical conditions, and necessitate a global analysis of the patient, and place particular importance on the recent history of trauma for the diagnosis.

No brain injury will be evident on MRI or CT scans with an uncomplicated concussion; however, structural axonal injury may be present-just not evident on imagingand concussions may be complicated by coexisting intracranial hematomas, petechial hemorrhages in areas with blood vessel shearing, or cortical contusions. If a concussion occurs while an individual is still symptomatic from an earlier concussive event, the theoretical and controver-

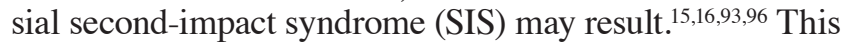
syndrome describes a situation in which the second trauma causes a loss of cerebral autoregulation with resultant and cerebral edema, which can be seen on brain imaging. This topic is discussed in greater detail later in the review.

\section{Associated Injuries}

The CNS pathology most commonly associated with mTBI includes axonal injury, brain contusions, and intracranial hemorrhages (ICHs). The primary pathological feature of TBI is axonal shear injury. ${ }^{153}$ The damage to the axons and small blood vessels is generally proportional to applied traumatic force, and the extent of axonal injury is suggested by the duration of LOC or the amnesia and GCS score following the injury. If vessels are damaged

TABLE 1. Common signs and symptoms of a concussion

\begin{tabular}{ll}
\hline Headache \\
\hline Sleep disturbances \\
\hline Dizziness \\
\hline Amnesia \\
\hline Nausea/vomiting \\
\hline Emotional changes/irritability \\
\hline Photophobia \\
\hline Difficulty concentrating/confusion \\
\hline Phonophobia \\
\hline Loss of balance \\
\hline Paresthesias \\
\hline Vision changes
\end{tabular}


along with the neuronal axons, the damaged areas may appear as petechial hemorrhages on CT or MRI scans.

Brain contusions are areas of focal cortical injury either from an external force or from rapid acceleration and deceleration that causes the brain to contact the intracranial surfaces. Contusions are associated with localized edema, ischemia, and mass effect, which collectively result in a worse outcome following an mTBI. ${ }^{148}$ Although signs of a contusion depend on its cortical location, any focal neurological signs should raise concern for a brain contusion.

Any type of ICH can occur after an mTBI, particularly if the patient is receiving anticoagulant therapy (albeit this is less common in the younger, athletic population). Any patient in whom an mTBI is diagnosed and who begins to show signs of neurological or clinical deterioration should be evaluated for an intracranial hematoma. It is possible that after an SRC a player may temporarily regain consciousness or have an improvement in neurological status before slipping into an unconscious state. This history of a lucid interval following a serious head trauma is a strong indication that a potentially life-threatening complication of the head injury, classically an epidural hematoma, is causing this rapid deterioration after a period of apparent improvement. During the period in which the patient is improving, blood is collecting in the epidural space, and as it accumulates the intracranial pressure rises, which compresses the brain parenchyma and leads to neurological dysfunction and potentially brain herniation. Although not a typical presentation, other complications, such as a cerebral contusion, subdural hematoma, pseudoaneurysm rupture, or ICH can also cause a lucid interval.

\section{Complications of Mild Head Trauma}

Skull fractures can complicate even mild traumatic blows to the head. These fractures can either be linear or depressed. Although linear fractures are often benign, they can be associated with underlying pathology such as brain contusions, dural tears, and vascular trauma. ${ }^{29} \mathrm{~A}$ basilar skull fracture can lead to intracranial infections and CSF leakage if a fistula is created, resulting in otorrhea. Likewise, a frontal bone fracture can lead to CSF rhinorrhea and CNS infection if the ethmoid bone shears the olfactory nerves. Any type of fracture that leads to communication between air and the intracranial compartment is classified as an open head injury and should be evaluated with a neurosurgical consultation.

Screening for cervical spine injury should be performed, with history, examination, and imaging studies. Furthermore, vascular injury within the neck can occur. Additionally, trauma can result in cavernous sinus syndrome. Signs of cavernous sinus syndrome include Horner syndrome, ophthalmoplegia, chemosis, proptosis, and trigeminal sensory loss.

Eye injuries may require an ophthalmology consultation if the trauma involves frontal impact. Any cranial nerve injuries that fail to improve as the perineural edema resolves raise suspicion for a nerve entrapment, and neurosurgical consultation is advised.

\section{Pathophysiology of Concussion}

Although a tissue sample is not indicated during the diagnosis and management of a concussion, this type of trauma is thought to represent a very mild form of diffuse axonal injury with no permanent histological changes. At the cellular level, the axonal stretching from a traumatic force results in mechanoporation, or a disruption in the neural membrane, which allows for an efflux of $\mathrm{K}+$ and an influx of $\mathrm{Ca} 2+.{ }^{41,42}$ These ionic shifts trigger a release of glutamate, which results in an excitotoxic cascade and cognitive dysfunction.,59,85 The $\mathrm{Na}+\mathrm{K}+$ pump then tries to restore the ionic balance, and this coupled with mitochondrial dysfunction leads to insufficient adenosine 5'-triphosphate production and an increase in reactive oxygen species. ${ }^{149,150}$ The resultant adenosine 5'-triphosphate depletion and reactive oxygen species can generate a lactic acidosis and oxidative dysfunction. ${ }^{57}$ These neurometabolic and neurochemical irregularities in conjunction with changes in cerebral perfusion can result in confusion and possibly an LOC, particularly if the dysfunction occurs in the reticular activating system. ${ }^{67}$

There is also a growing interest in the role of inflammation in the pathogenesis of disease following a concussion, particularly with regard to postconcussive disease, which spans a spectrum of diseases including postconcussion syndrome (PCS), prolonged PCS (PPCS), chronic traumatic encephalopathy (CTE), mild cognitive impairment, and dementia pugilistica..$^{11,116}$

Briefly, following an SRC, the traumatic event in the CNS recruits neutrophils and monocytes, which in combination with the microglia and astrocytes already residing in the CNS, secrete inflammatory cytokines and alter their expression of signaling molecules to organize an immunological response. ${ }^{49}$ Glial fibrillary acidic protein expression, which is widely used as a marker for astrocyte activation, is significantly upregulated in patients who have suffered a brain injury when compared with controls who have suffered a traumatic nonbrain injury. ${ }^{102,155}$ In rodent models, the acute cytokine response following a concussion is remarkably complex but is thought to typically begin with an increase in the proinflammatory molecules interleukin (IL)-1 $\alpha$, IL-1 $\beta$, and tumor necrosis factor- $\alpha$ (TNF $\alpha) .{ }^{30}$ While levels of IL-1 $\alpha$ show an acute elevation and fall, IL-1 $\beta$ levels tend to remain elevated for a longer period, rise more than other proinflammatory cytokines, rise in an amount relative to the severity of the trauma, and spike more intensely if the concussion is associated with a contusion. ${ }^{48,151}$ Although some experiments have demonstrated that the increase in IL-1 $\beta$ expression precedes an increase in neuroprotective factors, others have demonstrated that inhibition of IL-1 $\beta$ expression following an mTBI leads to a reduction in cerebral edema and an improved cognitive outcome..$^{25,47}$ Likewise, TNF $\alpha$ appears to play both a neuroprotective and neurotoxic role in the CNS following mTBI, which may reflect differential binding of the molecule to its two CNS receptors. , $^{2139,154}$

More work is needed to determine how the severity of brain injury alters TNF $\alpha$ signaling, the time course for its protective and toxic activity, and how $\mathrm{TNF} \alpha$ interacts with other cytokines during the injury process. Additionally, overexpression of IL- 6 by astrocytes, which is potently stimulated by $\mathrm{TNF} \alpha$, has been shown to shorten recovery times following cortical freeze injury in mice by 
reducing apoptotic gene expression and regulating oxidative stress. ${ }^{123}$ Furthermore, IL-6 reduces the production of IL-1 $\beta$ and TNF $\alpha$, which may explain why mice deficient in IL-6 have exaggerated abnormalities following brain injury. ${ }^{64,69}$ Finally, it should not come as a surprise that antiinflammatory molecules, the predominant two being IL-10 and transforming growth factor $\beta$ (TGF $\beta$ ), are induced after the proinflammatory cytokines to form the negative feedback loop regulating the proinflammatory cascade. ${ }^{28}$ Unsurprisingly, the role of these antiinflammatory molecules is similarly murky following mTBI, with mixed results reported regarding their benefit or harm following injury. 132

The contribution of the immune response and neuroinflammation to both the immediate recovery following a concussion and the long-term sequelae of repetitive concussions should continue to be elucidated, because a thorough understanding of this mechanism may provide logical targets for the use of immunosuppressive agents as therapies to protect against the neurocognitive changes seen following multiple concussions. Nevertheless, some antiinflammatory treatment regimens, such as long-term ibuprofen administration or TNFo inhibitors, have either shown no benefit or adverse effects when used in patients with concussive symptoms or in rodent models of mTBI. ${ }^{13,76}$ It remains to be seen to what degree the immune activation following an SRC is protective versus harmful and if the immune system can be manipulated to benefit patients suffering from concussive symptoms.

\section{On-Field Diagnosis and Management}

Athletes should be evaluated if they show any signs or symptoms that are concerning for concussion. They should be evaluated immediately using standard emergency management and first aid and/or cardiopulmonary resuscitation principles including airway, breathing, and circulation, and particular attention should be paid to evaluation for a cervical spine injury. If a cervical spine injury cannot be ruled out, the participant must be immobilized with rigid orthotics, leaving on any sports equipment, such as a helmet and pads if applicable, and transferred to an emergency department capable of trauma evaluation and advanced neurological imaging. Additionally, if there is any sign of more serious brain injury (deteriorating mental status, localizing neurological deficit, abnormal results on pupillary examination, extraocular movement abnormalities, motor or sensory disturbances), the patient should be transferred for evaluation on an emergent basis. Once the appropriate initial disposition of the athlete is made by a health care provider on site, a concussion assessment may be performed on the sideline. However, if no health care provider is present, as is often the case in a practice setting, the participant should be removed from play and urgently referred to a physician.

First, the participant must be removed from play or practice. The assessment includes the use of standardized and validated symptom scoring scales of SRCs. These provide an easy to follow, systematic approach for on-field providers to use to evaluate and manage players, and they also provide a common language that may transfer longitudinally with the patient from various health care pro- viders during future health care appointments following the injury. Commonly used scales include the Pittsburgh Steelers postconcussion scale, ${ }^{83}$ the Concussion Resolution Index; ${ }^{34}$ the Postconcussion Symptom Scale; ${ }^{95}$ the Concussion Symptom Inventory; 126 and the Sport Concussion Assessment Tool (SCAT), third iteration, ${ }^{95}$ which is commonly referred to as SCAT3. If used in preseason physical assessments, these scales may also provide a baseline for future comparison should a postinjury evaluation be necessary. The remainder of the sideline evaluation includes a history and physical examination, primarily to rule out more serious neurological injuries.

Vision is an important assessment for concussion, although it is often underutilized during sideline assessment. Although not universally accepted as diagnostic, the King-Devick test is an oculomotor test that can be used for concussion screening in athletes. ${ }^{61,146}$ This test provides a rapid assessment of the visual pathways, and the results of numerous trials have shown that concussed athletes have significantly increased cumulative read times when compared with healthy controls, increasing the sensitivity of sideline evaluations. ${ }^{36,61,130}$

Balance and postural stability testing during sideline physical examination, especially when the results can be compared with preseason baselines, is very sensitive for the diagnosis of concussion. ${ }^{18,32,45,128}$ Standardized balance assessment tools are available to help diagnose concussions, and they include the Balance Error Scoring System $(\mathrm{BESS})^{45}$ and the Sensory Organization Test ${ }^{45}$ on the NeuroCom Smart Balance Master System (NeuroCom International, Inc.), which is used to identify musculoskeletal instability that becomes apparent only during balance testing. Studies have reported that acute postural instability deficits last approximately 72 hours following SRCs, ${ }^{18-}$ $20,44,45$ suggesting that postural stability is a useful tool for evaluating motor function following an mTBI. Formal testing using sophisticated clinical balance tests should be considered a reliable and valid addition to the assessment of an athlete who is suspected of having a concussion.

Standardized cognitive evaluation of the injured athlete allows trainers and team physicians to quickly assess and identify struggling athletes who have signs that might indicate a concussion. Common mental status questions used in our day-to-day practice, such as "What is your name?" "What is the year?" and "Where are we?" are often not sensitive for evaluation of a concussion.77.92 Maddocks and colleagues developed a series of questions that are more appropriate and accurate in assessing a possibly concussed athlete. These are integrated into the SCAT3 assessment, and include questions such as "What venue are we at?" "Who scored last?" "What half are we in?" "Did we win our last game?" and "Where did we play last week?"77,95 Other cognitive assessments that are quickly completed during the sideline evaluation include recalling 5 words, repeating a series of numbers backward, or listing the months of the year in reverse order.

Once a concussed athlete is identified, the athlete should be immediately removed from the field of play or practice and not allowed to return to athletic activities that day. A referral is made for further evaluation by health care providers to assess for a gradual, safe return to play. 


\section{In the Emergency Room}

Although many concussions go undiagnosed or present to outpatient clinics, athletes commonly will present to the emergency department for evaluation if they lose consciousness or have a cervical neck injury. This evaluation focuses on similar points to those discussed in the preceding section, with the addition of a more comprehensive history and detailed neurological examination, including mental status, cognitive, gait, and balance evaluations.

Additionally, because some time will have passed between the concussive event and presentation to the emergency department, it is important to identify whether there has been improvement or deterioration in the athlete's clinical status since the time of injury. Often, the athlete will be unable to recall the event, and additional information should be sought from parents, coaches, and teammates who witnessed the injury.

The evaluation of the concussed athlete in the emergency department must also include the determination of the need for emergency neurological imaging, which should be used when concern for intracranial or structural lesions exists. The utility of neuroimaging in the emergency department resides in identifying the rare instance when a lesion requires urgent neurosurgical intervention, such as an epidural hemorrhage. Although newer imaging modalities have provided evidence that abnormalities exist even in mild SRCs, as discussed later in this review, the current data have yet to provide conclusive evidence to support the use of these new modalities in routine assessments outside of the research setting. ${ }^{95}$

\section{Neuroimaging Techniques}

Most patients presenting with concussive symptoms do not require neurological imaging studies. In the emergency department, patients may receive a noncontrast head CT to quickly evaluate for any acute hemorrhagic event that requires urgent neurosurgical intervention. Alternatively, emergency medicine clinicians can choose to observe the patient for 4-6 hours and only obtain imaging if the patient has a worsening of clinical symptoms. Although MRI scans of the brain are more sensitive for small hematomas and axonal injury, these scans take much longer to complete and any additional findings rarely affect acute clinical management.

A wide range of neuroimaging modalities has been researched as potential tools to help investigate mTBI. These modalities include CT, PET, SPECT, and various MRI techniques such as diffusion tensor imaging (DTI), MR spectroscopy (MRS), arterial spin labeling, and functional MRI (fMRI). One potential role for neuroimaging is the determination of a complete recovery, because functional scans such as resting-state fMRI and MRS have shown that changes in neural network connectivity and metabolic imbalances lag behind cognitive and behavioral indices of recovery. ${ }^{10,53,54}$ Additionally, multimodal studies that use combinations of these imaging scans or serial scans to monitor patients during the healing process represent an exciting future tool in the management of patients after a concussion. ${ }^{107}$

The MRI modality has been reported to be more sensi- tive at detecting complicated mTBI than $\mathrm{CT},{ }^{104}$ and it also has the ability to examine a wide range of physical parameters by using various contrast settings. For example, "traditional" T1- and T2-weighted scans provide an idea of brain structure, fMRI correlates blood oxygenation levels (blood oxygenation level-dependent signal) with neural activity, diffusion MRI uses anisotropy to make inferences about axonal white matter microstructure, and MRS provides information about the biochemical changes in the brain. ${ }^{33}$

A meta-analysis of fMRI studies examining areas of neural activation following mTBI found that, spatially, activity was decreased in anterior brain regions like the frontal lobe and anterior cingulate, which are classically implicated in executive function and cognitive reasoning, and activity was increased in posterior brain regions like the cerebellum and foci in the parietal lobe. ${ }^{33}$ These findings led the authors to argue that there may be a vulnerability of frontal regions in the brain to mTBI. This finding of frontal vulnerability by fMRI is supported by white matter connectivity differences observed in DTI studies. ${ }^{33,72,108}$ Although these research studies are promising, there is still too much individual variability for these findings to be used in a clinically relevant manner. The ultimate goal of advanced neuroimaging modalities in patients with mTBI is to be able to predict an individual's timeline for recovery, identify transient and persistent cognitive deficits in conjunction with neuropsychiatric testing, and provide an objective measure that can quantify the success of behavioral and pharmacological interventions. ${ }^{88,121,122}$

The use of DTI for patients with mTBI is intriguing because this modality is particularly sensitive to white matter changes and may have the potential to detect diffuse axonal injury that occurs during mTBI. However, whereas one study found that DTI was the most sensitive MRI modality for detecting changes during the acute phase of mTBI, ${ }^{107}$ another study showed that no changes in fractional anisotropy (the most commonly used DTI-derived measure) were observed in patients with concussions approximately 30 days after their injury, ${ }_{152}$ and generally the studies of DTI in patients with mTBI have produced inconsistent reports. ${ }^{131}$

Given the metabolic disturbances that occur in the concussed brain, MRS, which measures brain metabolites, is a promising modality for determining the cascade of molecular changes seen following mTBI. In a recent review, the most significant finding was a reduction in $\mathrm{N}$-acetylaspartate, which is believed to be a specific neuronal marker. ${ }^{37}$ Although there was considerable variability in the MRS collection and analysis across the studies reviewed, there may be diagnostic potential for MRS in SRCs; 9 of the 11 studies examined found metabolic differences between athletes and control subjects, and these changes were evident in the acute and subacute postinjury stages. Although the use of MRS is still experimental, as more work is done to explore the correlations between concussion severity and timing of recovery with metabolic changes such as decreases in $N$-acetylaspartate, there may be a role for MRS in the clinic and emergency department in the future. 


\section{Treatment}

\section{General Management of SRCs and Return to Play}

Individuals usually recover from SRCs within days to weeks, with complete resolution of symptoms and cognitive improvement. ${ }^{14,43,95}$ General management of SRCs focuses on mental and physical rest until an athlete is symptom free. Following this clinical improvement, a graduated increase in physical activity is instituted before an individual may return to play. ${ }^{95}$

In its "Heads Up to Health Care Providers" campaign, the Centers for Disease Control and Prevention published return-to-play steps adapted from the International Concussion Consensus Guidelines to help safely return athletes to play (Table 2). ${ }^{95}$ This graduated, stepwise return-to-play protocol is also supported by the American Academy of Pediatrics ${ }^{86}$ Each stage of the graduated increase is expected to take 24 hours, and the athlete must remain asymptomatic to qualify to proceed to the next tier of activity. If any symptoms return, the athlete is probably pushing too hard to return and should stop all physical activity. In that situation, the athlete is instructed to rest for 24 hours, and then return to the previous phase and resume activity at that level. Once the athlete is again asymptomatic at that level, they may continue to proceed to gradually increasing levels of activity and continue toward returning to play, as long as they remain symptom free. ${ }^{89}$ Most athletes will recover quickly and fully after a concussion, but should symptoms worsen at any time, remain present for greater than 10-14 days, or if athletes have a history of multiple concussion or mood disorders, a referral to a concussion specialist is warranted. It is the current practice of the senior author to evaluate athletes with a suspected SRC in a formal clinical setting before clearing them to return to the field of play.

The American Academy of Neurology has also pub-

\section{TABLE 2. Graduated return-to-play protocol in athletes with} concussions

\section{Baseline: no symptoms \\ The first step in the return-to-play progression requires that the ath- lete complete physical and cognitive tests and be symptom free for a minimum of 24 hours. For younger athletes more conserva- tive restrictions can be used. \\ Step 1: light aerobic activity \\ 5-10 minutes of light aerobic activity, such as walking, light jogging, or riding an exercise bike, with the goal of increasing the heart rate.}

Step 2: moderate activity

Moderate jogging, brief running, or moderate-intensity weightlifting that is reduced from the typical routine, with a goal of limited body and head movement.

Step 3: heavy, non-contact activity

Intense activity that is close to the typical routine but non-contact. There may be some added cognitive component to practice during this step.

Step 4: practice and full contact

Reintegrate the athlete into full-contact practice.

Step 5: competition

Return to competition. lished an evidence-based guideline for managing athletes with concussion. ${ }^{43}$ This guideline recommends immediate removal from play of an athlete with a concussion until they can be assessed by a licensed health care professional trained in recognizing concussion. The guideline recommends assessing each athlete individually, with no set timeline for safe return to play. For example, high school and younger athletes should be managed more conservatively, because they can take longer to recover than college athletes. This guideline also concludes that absolute rest during concussion recovery is not supported with sufficient evidence, and therefore activities that do not worsen symptoms and do not pose a risk of repeat concussion may be included in the concussion management plan.

\section{Neurosurgical Management}

The vast majority of patients with SRCs or mTBI present with a GCS score of 14-15 and do not require neurosurgical intervention. Accordingly, the American College of Emergency Physicians' 2008 policy on mTBI recommends discharging patients unless they have an $\mathrm{ICH} .{ }^{52} \mathrm{In}$ contrast, patients with ICH, regardless of severity, are typically observed in the ICU. ${ }^{117,147}$

One study using the National Trauma Data Bank found that in adult patients with an ICD-9 diagnosis of intracranial injury and a GCS score of 14-15 in the emergency department who were admitted to the hospital, isolated subdural hemorrhages were the most common injury observed (37\% of patients). ${ }^{141}$ Subarachnoid hemorrhages were the second most common injury (26\% of patients), and the rate of neurosurgical intervention was $8.8 \%$. Epidural hemorrhages most frequently required neurosurgical intervention, whereas subarachnoid hemorrhages and contusions required surgical intervention least frequently. Furthermore, given the large number of subdural hemorrhages observed, they represented the most common ICH complicating mTBI to require neurosurgery. Perhaps as expected, patients with coagulopathy or abnormal fibrinolysis are more likely to deteriorate following mild to moderate TBI and require surgery.

\section{Pharmacological Treatment}

To date, there have been no studies that demonstrate that pharmacological treatments are effective at speeding the recovery from a concussion or diminishing the deficits attributed to the injury. ${ }^{8,118}$ In fact, there is a great need for large-scale, multicenter studies to evaluate the benefits of medications for treating prolonged postconcussion symptoms and to determine if there is any benefit to neuroprotective therapies. Nevertheless, patients who are experiencing prolonged symptoms (either PCS or PPCS) that significantly impact their daily activities may benefit from medical treatment of their ongoing symptoms. The decision to treat with pharmacological agents must be made on an individual basis and should take into account the degree and duration of impairment from the symptoms and the potential adverse effects of starting a medication.

Petraglia et al. provide an excellent review of the pharmacotherapeutics used to treat the somatic complaints, sleep disturbances, emotional difficulties, and cognitive difficulties that may exist following mTBI. ${ }^{118}$ In general, 
agents should be started at their lowest effective dose and slowly titrated up to maximize clinical response and minimize side effects. Furthermore, agents that may contribute to the confusion and cognitive slowing seen in the patient should be avoided so as to not confound the patient's clinical examination with a drug's adverse effects. Furthermore, it is advisable to attempt to avoid medications that are known to lower the seizure threshold.

Considerable effort has been expended to investigate whether naturally occurring supplements and compounds that may possess antiinflammatory or neuroprotective effects could be beneficial in the aftermath of a concussion. ${ }^{119}$ Although human studies are lacking, these agents may address the underlying pathophysiological processes responsible for the long-term symptoms following concussions, and offer a relatively limited side-effect profile.

For instance, long-chain polyunsaturated fatty acids are an important structural component of the neuronal synaptosomal plasma membrane, but they are underrepresented among the other lipids consumed via our dietary intake. The benefit of pretraumatic supplementation of docosahexaenoic acid (DHA), a long-chain polyunsaturated fatty acid, has been demonstrated in multiple rodent models of TBI. ${ }^{119}$ In rodents, DHA supplementation has been shown to be neuroprotective following either focal or diffuse TBI, to reduce the number of damaged axons, to reduce excitotoxicity, and to provide numerous other multimechanistic benefits to the posttraumatic brain. Well-designed trials will be required to determine whether DHA supplementation in athletes may improve outcomes following SRCs. Green tea is another commonly discussed product that contains many natural compounds that have been investigated for their potentially neuroprotective antioxidant and antiinflammatory properties..$^{23,55,56,66,80}$ One study demonstrated that green tea reduced the amount of tau phosphorylation and beta-amyloid deposition in a mouse model of Alzheimer disease, which may be relevant given the pathological findings in CTE. ${ }^{127}$ These substances provide a small snapshot of the potential value of natural supplements for both the prevention and treatment of concussions, and human studies are necessary to determine how and when their use will benefit athletes in a practical, cost-effective, and well-tolerated manner.

In the future, there is the potential for advanced imaging techniques such as fMRI to help guide our use of medications in the management of postconcussion symptoms. For example, fMRI studies have shown that postconcussion depression shares underlying pathophysiological features with the limbic-frontal model of depression and may be amenable to treatment with traditional antidepressive agents..$^{21,22}$ Biomarkers may also serve a future role in the identification of patients whose symptoms are likely to persist and who thus may require upfront management with pharmacological agents rather than a watchful waiting approach.

\section{Postconcussion Syndrome, SIS, and CTE Postconcussion Syndrome}

As stated previously, the neurological effects of SRCs are typically transient-approximately $90 \%$ of high school athletes are symptom free and back at their neurological baseline within 1 month of the traumatic event. ${ }^{35,79,82,93,101}$ However, a small percentage of athletes will continue to experience symptoms months after the initial injury; this is termed PCS. Common symptoms of PCS are often vague and nonspecific, making the diagnosis difficult. The primary complaint of an athlete suffering from PCS can be any symptom of concussion; the most commonly reported symptoms are headache, dizziness, insomnia, exercise intolerance, cognitive intolerance, depressed mood, irritability, anxiety, memory loss, poor concentration and problem solving, fatigue, photo- and/or phonophobia, and psychiatric complaints. ${ }^{1,63,73}$ These late disabilities from the concussive event are frequently self-reported and appear to be inversely related to the severity of the injury. To date no evidence exists that correlates PCS with severity of injury, structural damage to the brain, or disruption of neurotransmitter cascades. ${ }^{46}$

Morgan et al. recently identified preinjury mood or psychiatric disorders, a family history of mood disorders, the number of previously sustained concussions, and delayed symptomatology (defined as symptom onset occurring more than 3 hours postinjury) as predictors of PCS development in high school athletes after an SRC. ${ }^{106}$ Interestingly, this multivariate model indicated that a history of a preinjury mood disorder was much more significant for predicting the development of PCS than the number of previous concussions. The results of this study support previous findings that children with high levels of stress in their lives, a history of mood disorders, and children whose parents have mood or anxiety disorders have an increased risk of prolonged problems after suffering mild head injury. ${ }^{109}$ Another study examining the health consequences of PCS in children found that there was a 3.3fold increase in depression after head injury, and that this increases to 4.8-fold when a parent had a mental health diagnosis. ${ }^{24}$ Providers need to be aware that these postconcussion symptoms exist and know the risk factors for their development, identify patients who are at the greatest risk, and monitor them closely.

A current area of concern among providers is the effect of repetitive mTBIs, subconcussive head impacts or concussion-generating impacts, and the development of SIS and CTE in the injured athlete.

\section{Second-Impact Syndrome}

Second-impact syndrome is a feared complication of returning to play too early after a concussive event, and suffering a repeat injury, before symptoms from a previous injury have resolved. ${ }^{15,16}$ This syndrome, which is also called "diffuse cerebral swelling," is thought to involve the loss of autoregulation of the brain's blood supply, leading to vascular engorgement and elevated cerebral blood volume, as well as a marked increase in intracranial pressure, and ultimately can cause a herniation event resulting in coma or death. It is still widely debated whether this phenomenon exists as a sequela of prior head injury or if it represents a separate pathophysiological process of malignant cerebral edema seen in younger athletes. The literature on this etiology is sparse and case reports often describe young athletes $(<18$ years old), in whom 
the pathophysiology and clinical history presented occasionally does not support the diagnosis of SIS. Of the 17 case reports of SIS identified, only 5 involved repeat injuries, all of which occurred within 7 days of the initial injury. ${ }^{93,96}$ However, whether or not SIS exists as classically defined, the association with early, repeat concussive injury warrants that the injured athlete not return to play before the symptoms of the concussion have completely resolved.

Apart from SIS, allowing an athlete to return to play prior to symptom resolution predisposes them to more severe injury from a subsequent concussion, with a prolonged duration and increased severity of symptoms. A previous concussion decreases the cognitive ability and reaction time of the individual, increasing the athlete's susceptibility to repeat injury due to their diminished ability to respond to the demands of the sport. ${ }^{74,75,91,95,134,140}$ There theoretically exists a time window of increased brain vulnerability due to the impaired cellular energy metabolism, during which a repetitive injury would worsen these neurochemical and neurometabolic derangements, leading to more significant cognitive deficits and prolonged recovery. ${ }^{62,78,133,143-145}$

The growing concern over the consequences of repetitive concussive and subconcussive injuries among American athletes is evident in today's media. Subconcussion is due to a biomechanical force applied to the cranial contents that does not result in clinical signs or symptoms sufficient to diagnose a concussion. The mechanism of injury may be due to direct impact; acceleration-deceleration or rotation of the head; or the "slosh" phenomenon, which is described as acute acceleration or deceleration of the body, with resultant brain movement within the cranial vault leading to injury. ${ }^{135}$ Although no overt signs are present on the initial injury, the clinical consequence of subconcussions is manifested as a result of the athlete's cumulative exposure. ${ }^{3}$ Concussion-free college athletes participating in contact sports demonstrated lower scores on formal neuropsychological testing, notably in new learning and memory domains, than did control individuals. ${ }^{60,87}$ Among athletes exposed to subconcussive injuries, some studies have shown that the deterioration in cognitive performance is directly proportional to their exposure burden, although other studies have failed to reproduce this phenomenon. ${ }^{87,103}$ When nonconventional neuroimaging is used, athletes without observable symptoms of a concussion have demonstrated neurophysiological changes that are similar to those seen on fMRI activation during working memory tasks in control patients with known concussion. ${ }^{12,142}$ These changes appear to be statistically correlated with the number of subconcussive hits sustained by the athlete. ${ }^{12}$

Additionally, DTI has provided evidence of white matter damage in subconcussion brain injuries, although the clinical significance of these lesions has yet to be determined.? Unfortunately, our knowledge of subconcussions remains in its infancy, and although data strongly suggest the presence of detrimental neurological consequences secondary to the repetitive exposure by athletes, further research is needed if we are to understand the true scope of this entity.

\section{Chronic Traumatic Encephalopathy}

Recent evidence suggests that CTE is a potential longterm neurological sequela of repetitive brain injury, although a direct, causal mechanistic linkage has yet to be discovered. Neurological and neurobehavioral symptoms in contact sports were first described in boxers in the 1920 s and 1930s - initially referred to as "punch drunk" syndrome-who developed parkinsonism, dysarthria, and psychiatric disturbances ${ }^{84,115}$ (which were also colloquially known as "traumatic encephalopathy," "dementia pugilistica," and "chronic traumatic encephalopathy"). In the 1970s, researchers began to examine and categorize the neuropathological changes they discovered in boxers diagnosed with dementia pugilistica, ${ }^{27}$ and in the late 1990s, the association between repetitive head injuries and neocortical neurofibrillary tangle formation and tau pathology was identified..$^{39}$ In 2005, Omalu et al. reported the first case of CTE in a retired National Football League player, ${ }^{114}$ with a second case reported 1 year later. ${ }^{113}$ McKee et al. described 48 cases in the world literature as of $2009,{ }^{97}$ and a few years later proposed a pathological staging system to categorize CTE. ${ }^{100}$

However, despite multiple authors describing a similar syndrome, the exact clinical features and pathological findings that are necessary and sufficient to constitute CTE remains unanswered. For instance, suicidality is widely cited as a clinical feature of CTE:51 it was first described by Omalu et al. in 2010 after patients in 2 of the 3 cases examined committed suicide. ${ }^{112}$ However, in the exhaustive 2009 review by McKee et al., suicide was not reported in a single case, nor was it included in their description of CTE's clinical features. ${ }^{97}$

The most widely accepted etiological description of CTE assumes an associative relationship with multiple concussions in sports: ${ }^{100,111,136}$ however, a single $\mathrm{TBI}^{111}$ or multiple mTBIs in military personnel and civilians ${ }^{100,111,136}$ have been identified as possible causes. Lately, the role of subconcussion and the development of CTE has come to the forefront of many investigators' endeavors, in which this "silent" epidemic is cited as possibly a larger problem than classically diagnosed concussions. ${ }^{3,6,38,97}$

The evolution of neuropathological and clinical descriptions of CTE continues to be refined. Omalu et al. originally described the clinical presentation of CTE as a progressive deterioration in social and cognitive functioning, mood and behavioral disorders, progressive deterioration in interpersonal relationships, violent behavior, substance abuse, headaches and/or body aches, and increasing religiosity. ${ }^{11}$ Additionally, some have described an insidious onset, often initially manifesting as disturbances in attention, difficulty concentrating, or depression, with or without headaches. ${ }^{31}$ Athletes often begin showing symptoms between the ages of 35 and 45 years (range $24-65$ years), ${ }_{100}$ with a characteristic latent period of approximately 8 years between the last trauma and the development of symptoms. ${ }^{97}$ There are data that suggest CTE may present as one of three clinical pictures: CTE onset at younger age with predominant behavioral or mood disturbances; CTE onset later in life with predominantly cognitive impairment; or CTE with a mixed picture of both cognitive and behavioral and/or mood disturbances. ${ }^{105,137}$ The onset and 
severity of CTE symptoms may be associated with the burden of hyperphosphorylated tau deposition, neuroinflammation, and axonal pathology in the injured patient..$^{31}$

Recent descriptions of the microscopic neuropathology include the following: localized neuronal and glial accumulation of tau in perivascular areas of the cerebral cortex, sulcal depths, and superficial cortical lamina; multifocal axonal varicosities in subcortical and deep white matter; variable and sometimes absent beta-amyloid deposits; and immunohistological TAR DNA-binding protein 43 (TDP-43)-positive inclusions and neurites. ${ }^{6,38,99}$ These pathological findings may also be found in other conditions including Alzheimer disease, frontotemporal dementia, progressive supranuclear palsy, and aging; however, the localization of tau as described above is considered unique and is a distinguishing characteristic for CTE.$^{51}$

McKee et al. proposed a 4-stage pathological description of CTE in 2013 that represents a progressive description of the disease, with symptom onset and evolution associated with the severity of macro- and microscopic changes observed in gross specimens. ${ }^{100}$

Stage I is often asymptomatic or associated with onset of nonspecific symptoms such as headache, irritability, and decreased concentration. ${ }^{100}$ On pathological examination, the brain is grossly unremarkable. Microscopically, one or two isolated perivascular foci of tau deposition are identified, often at the depths of cerebral sulci in the frontal cortex and subpial astrocytes. Vascular amyloid deposits and beta-amyloid plaques are not found. ${ }^{98}$

Athletes with Stage II CTE are often symptomatic and exhibit short-term memory difficulties, disorganization and difficulty planning, aggression, mood swings and/or depression, explosivity, and suicidality ${ }^{100,137}$ Half of the pathological specimens show macroscopic changes including mild enlargement of the lateral and third ventricles, cavum septum pellucidum, and pallor of the substantia nigra and locus coeruleus. Multiple foci of tau pathology are identified in sulcal depths throughout the supratentorial cortex, with neurofibrillary tangles found in superficial layers of adjacent cortex. Deep structures (thalamus, median and dorsal raphe, and substantia nigra) show mild neurofibrillary degeneration. Perivascular beta-amyloid and beta-amyloid plaques are rarely identified. ${ }^{8}$

By Stage III, most athletes are cognitively impaired due to memory loss, executive dysfunction, and attention deficits, in addition to the previously mentioned symptoms in earlier stages..$^{51,71,98}$ Macroscopically, there is reduced brain weight; mild frontal and temporal atrophy; lateral and third ventricular enlargement; septum abnormalities; atrophy of mammillary bodies, thalamus, and hypothalamus; thinning of the corpus callosum; and pallor of the locus coeruleus and substantia nigra. Microscopically, neurofibrillary tangles are identified in the sulcal depths and perivascular areas throughout the frontal, temporal, and parietal cortices. Additionally, the hippocampus, amygdala, entorhinal cortex, nucleus basalis of Meynert, and locus coeruleus display extensive neurofibrillary tangles, with less prominent foci now identified in the hypothalamus and mammillary bodies. Beta-amyloid deposits and plaques continue to become more prominent. ${ }^{98}$

Stage IV CTE is associated with severe executive dys- function and memory loss with dementia. Most athletes suffer from profound loss of concentration and attention, language difficulties, paranoia, depression, difficulty with gait, visuospatial disturbance, aggression, and explosivity. ${ }^{97,98,105}$ Macroscopically, there is significant frontal, lateral, and medial temporal, and also anterior thalamic atrophy. The mammillary bodies are darkly discolored and atrophied, the hypothalamic floor is thinned, and there is marked enlargement of the lateral and third ventricles, in addition to the findings described in Stage III. Microscopically, severe spongiosus of cortical layer 2 and neuronal loss is widespread. The white matter of the cerebral hemispheres displays marked myelin loss and astrocytosis, perivascular macrophage deposition, and severe tau clusters and neurofibrillary tangles throughout the frontal, temporal, and parietal cortices. The insula, septal area, temporal cortex, amygdala, hippocampus, entorhinal cortex, substantia nigra, and locus coeruleus show severe neurofibrillary degeneration. ${ }^{98}$

Despite this exhaustive description of the pathological stages by McKee et al., other researchers found different pathological changes in patients identified as having CTE. Omalu et al. ${ }^{111}$ reported that CTE is not associated with cerebral atrophy, in contrast to the previously mentioned findings by McKee et al., ${ }^{100}$ in which it was a prominent characteristic. Additionally, McKee et al. described tau immunoreactive astrocytic tangles as a defining feature of CTE, but these were not present in the series published by Omalu et al. ${ }^{100,111}$ Microscopically, there is a discrepancy regarding subependymal accumulation of tau, which was described by McKee et al., but again not identified by Omalu et al., although both agree on the characterization of CTE by tau deposition in sulcal depths and superficial cortical layers. ${ }^{100,111}$

It is important to appreciate that many cases identified as CTE also showed other nonspecific neuropathological changes, in addition to many cases meeting neuropathological criteria for the diagnosis of other neurodegenerative diseases such as frontotemporal dementia and Alzheimer disease..$^{51}$ These objective findings, along with the frequent overlapping of similar symptoms, make distinguishing CTE from other disorders difficult.

Going forward, there are several important issues regarding CTE that must be addressed. A set of consensusbased, specific, sufficient, and reproducible criteria for the neuropathological diagnosis of CTE needs to be established, with which control subjects can be analyzed to understand what pathological changes are attributable to CTE as compared with other neurodegenerative disorders and/or the normal aging process. The lack of control subjects in the prior pathological studies of CTE should not be minimized. These criteria may enable us to better qualify to what degree and by what mechanism tau deposition might cause or reflect the progressive degeneration and/or clinical symptoms of CTE.

Other areas of debate include identifying a clinical methodology to determine to what extent a patient's symptoms are attributable to CTE versus other neurological, psychiatric, medical, and degenerative processes; identifying to what extent repetitive neurotrauma uniquely contributes to clinical symptoms of CTE; $6,38,97,100,110,112,137,138$ 
and identifying whether the changes attributed thus far to repetitive neurotrauma represent a distinct disease process, or whether the repetitive injuries are associated with reductions in cerebral reserve that result in an increased vulnerability to earlier expression of late-life neurodegenerative disorders. ${ }^{58,124,125}$ Until our knowledge of CTE becomes more complete, and causality is identified, our best management strategy remains prevention. If the data suggestive of neurotrauma as an inciting factor prove to be true, better equipment, rule changes, and increased awareness will, it is hoped, result in a reduction in incidence of $\mathrm{CTE}$ in the future.

\section{Conclusions}

A growing body of data suggests a link between repetitive SRCs and short- and long-term neurological consequences. These findings have been transformative in today's sporting world, with the implementation of numerous rule changes and increased educational endeavors focusing on SRCs. Although future research in the field of TBI appears promising, with continued identification of underlying pathophysiological processes and possible therapeutic pathways, prevention remains the ideal strategy for protecting athletes. Continued education of athletes, parents, coaches, and health care providers regarding recognition and management of SRCs is of the utmost importance as we continue to investigate this issue.

\section{References}

1. Alexander MP: Mild traumatic brain injury: pathophysiology, natural history, and clinical management. Neurology 45:1253-1260, 1995

2. Arnett HA, Mason J, Marino M, Suzuki K, Matsushima GK, Ting JP: TNF $\alpha$ promotes proliferation of oligodendrocyte progenitors and remyelination. Nat Neurosci 4:11161122,2001

3. Bailes JE, Petraglia AL, Omalu BI, Nauman E, Talavage $\mathrm{T}$ : Role of subconcussion in repetitive mild traumatic brain injury. J Neurosurg 119:1235-1245, 2013

4. Bakhos LL, Lockhart GR, Myers R, Linakis JG: Emergency department visits for concussion in young child athletes. Pediatrics 126: e550-e556, 2010

5. Barkhoudarian G, Hovda DA, Giza CC: The molecular pathophysiology of concussive brain injury. Clin Sports Med 30:33-48, vii-iii, 2011

6. Baugh CM, Stamm JM, Riley DO, Gavett BE, Shenton ME, Lin A, et al: Chronic traumatic encephalopathy: neurodegeneration following repetitive concussive and subconcussive brain trauma. Brain Imaging Behav 6:244-254, 2012

7. Bazarian JJ, Zhu T, Blyth B, Borrino A, Zhong J: Subjectspecific changes in brain white matter on diffusion tensor imaging after sports-related concussion. Magn Reson Imaging 30: 171-180, 2012

8. Beauchamp K, Mutlak H, Smith WR, Shohami E, Stahel PF: Pharmacology of traumatic brain injury: where is the "golden bullet"? Mol Med 14:731-740, 2008

9. Benson BW, Hamilton GM, Meeuwisse WH, McCrory P, Dvorak J: Is protective equipment useful in preventing concussion? A systematic review of the literature. Br J Sports Med 43 (Suppl 1):i56-i67, 2009

10. Bigler ED: Mild traumatic brain injury: the elusive timing of "recovery". Neurosci Lett 509:1-4, 2012

11. Blaylock RL, Maroon J: Immunoexcitotoxicity as a central mechanism in chronic traumatic encephalopathy-A unifying hypothesis. Surg Neurol Int 2:107, 2011
12. Breedlove EL, Robinson M, Talavage TM, Morigaki KE, Yoruk U, O'Keefe K, et al: Biomechanical correlates of symptomatic and asymptomatic neurophysiological impairment in high school football. J Biomech 45:1265-1272, 2012

13. Browne KD, Iwata A, Putt ME, Smith DH: Chronic ibuprofen administration worsens cognitive outcome following traumatic brain injury in rats. Exp Neurol 201:301-307, 2006

14. Cancelliere C, Hincapié CA, Keightley M, Godbolt AK, Côté P, Kristman VL, et al: Systematic review of prognosis and return to play after sport concussion: results of the International Collaboration on Mild Traumatic Brain Injury Prognosis. Arch Phys Med Rehabil 95 (3 Suppl):S210S229, 2014

15. Cantu RC: Second-impact syndrome. Clin Sports Med 17:37-44, 1998

16. Cantu RC, Gean AD: Second-impact syndrome and a small subdural hematoma: an uncommon catastrophic result of repetitive head injury with a characteristic imaging appearance. J Neurotrauma 27:1557-1564, 2010

17. Carroll LJ, Cassidy JD, Holm L, Kraus J, Coronado VG: Methodological issues and research recommendations for mild traumatic brain injury: the WHO Collaborating Centre Task Force on Mild Traumatic Brain Injury. J Rehabil Med 43 Suppl:113-125, 2004

18. Cavanaugh JT, Guskiewicz KM, Giuliani C, Marshall S, Mercer V, Stergiou N: Detecting altered postural control after cerebral concussion in athletes with normal postural stability. Br J Sports Med 39:805-811, 2005

19. Cavanaugh JT, Guskiewicz KM, Giuliani C, Marshall S, Mercer VS, Stergiou N: Recovery of postural control after cerebral concussion: new insights using approximate entropy. J Athl Train 41:305-313, 2006

20. Cavanaugh JT, Guskiewicz KM, Stergiou N: A nonlinear dynamic approach for evaluating postural control: new directions for the management of sport-related cerebral concussion. Sports Med 35:935-950, 2005

21. Chen JK, Johnston KM, Collie A, McCrory P, Ptito A: A validation of the post concussion symptom scale in the assessment of complex concussion using cognitive testing and functional MRI. J Neurol Neurosurg Psychiatry 78:1231-1238, 2007

22. Chen JK, Johnston KM, Frey S, Petrides M, Worsley K, Ptito A: Functional abnormalities in symptomatic concussed athletes: an fMRI study. Neuroimage 22:68-82, 2004

23. Cheng X, Zhang L, Lian YJ: Molecular targets in Alzheimer's disease: from pathogenesis to therapeutics. BioMed Res Int 2015:760758, 2015

24. Chrisman SP, Richardson LP: Prevalence of diagnosed depression in adolescents with history of concussion. $\mathbf{J}$ Adolesc Health 54:582-586, 2014

25. Clausen F, Hånell A, Björk M, Hillered L, Mir AK, Gram $\mathrm{H}$, et al: Neutralization of interleukin- $1 \beta$ modifies the inflammatory response and improves histological and cognitive outcome following traumatic brain injury in mice. Eur J Neurosci 30:385-396, 2009

26. Collins MW, Iverson GL, Lovell MR, McKeag DB, Norwig J, Maroon J: On-field predictors of neuropsychological and symptom deficit following sports-related concussion. Clin J Sport Med 13:222-229, 2003

27. Corsellis JA, Bruton CJ, Freeman-Browne D: The aftermath of boxing. Psychol Med 3:270-303, 1973

28. Csuka E, Morganti-Kossmann MC, Lenzlinger PM, Joller $\mathrm{H}$, Trentz O, Kossmann T: IL-10 levels in cerebrospinal fluid and serum of patients with severe traumatic brain injury: relationship to IL- 6 , TNF- $\alpha$, TGF- $\beta 1$ and blood-brain barrier function. J Neuroimmunol 101:211-221, 1999

29. Dacey RG Jr, Alves WM, Rimel RW, Winn HR, Jane JA: 
Neurosurgical complications after apparently minor head injury. Assessment of risk in a series of 610 patients. $\mathbf{J}$ Neurosurg 65:203-210, 1986

30. Dalgard CL, Cole JT, Kean WS, Lucky JJ, Sukumar G, McMullen DC, et al: The cytokine temporal profile in rat cortex after controlled cortical impact. Front Mol Neurosci 5:6, 2012

31. Daneshvar DH, Goldstein LE, Kiernan PT, Stein TD, McKee AC: Post-traumatic neurodegeneration and chronic traumatic encephalopathy. Mol Cell Neurosci 66 (Pt B):81-90, 2015

32. Davis GA, Iverson GL, Guskiewicz KM, Ptito A, Johnston KM: Contributions of neuroimaging, balance testing, electrophysiology and blood markers to the assessment of sportrelated concussion. Br J Sports Med 43 (Suppl 1):i36-i45, 2009

33. Eierud C, Craddock RC, Fletcher S, Aulakh M, King-Casas B, Kuehl D, et al: Neuroimaging after mild traumatic brain injury: review and meta-analysis. Neuroimage Clin 4:283294, 2014

34. Erlanger D, Feldman D, Kutner K, Kaushik T, Kroger H, Festa J, et al: Development and validation of a web-based neuropsychological test protocol for sports-related returnto-play decision-making. Arch Clin Neuropsychol 18:293316,2003

35. Frommer LJ, Gurka KK, Cross KM, Ingersoll CD, Comstock RD, Saliba SA: Sex differences in concussion symptoms of high school athletes. J Athl Train 46:76-84, 2011

36. Galetta KM, Morganroth J, Moehringer N, Mueller B, Hasanaj L, Webb N, et al: Adding vision to concussion testing: a prospective study of sideline testing in youth and collegiate athletes. J Neuroophthalmol 35:235-241, 2015

37. Gardner A, Iverson GL, Stanwell P: A systematic review of proton magnetic resonance spectroscopy findings in sportrelated concussion. J Neurotrauma 31:1-18, 2014

38. Gavett BE, Cantu RC, Shenton M, Lin AP, Nowinski CJ, McKee AC, et al: Clinical appraisal of chronic traumatic encephalopathy: current perspectives and future directions. Curr Opin Neurol 24:525-531, 2011

39. Geddes JF, Vowles GH, Nicoll JA, Révész T: Neuronal cytoskeletal changes are an early consequence of repetitive head injury. Acta Neuropathol 98:171-178, 1999

40. Gessel LM, Fields SK, Collins CL, Dick RW, Comstock RD: Concussions among United States high school and collegiate athletes. J Athl Train 42:495-503, 2007

41. Giza CC, Hovda DA: The neurometabolic cascade of concussion. J Athl Train 36:228-235, 2001

42. Giza CC, Hovda DA: The new neurometabolic cascade of concussion. Neurosurgery 75 (Suppl 4):S24-S33, 2014

43. Giza CC, Kutcher JS, Ashwal S, Barth J, Getchius TS, Gioia GA, et al: Summary of evidence-based guideline update: evaluation and management of concussion in sports: report of the Guideline Development Subcommittee of the American Academy of Neurology. Neurology 80:22502257,2013

44. Guskiewicz KM: Assessment of postural stability following sport-related concussion. Curr Sports Med Rep 2:24-30, 2003

45. Guskiewicz KM, Ross SE, Marshall SW: Postural stability and neuropsychological deficits after concussion in collegiate athletes. J Athl Train 36:263-273, 2001

46. Harmon KG, Drezner JA, Gammons M, Guskiewicz KM, Halstead M, Herring SA, et al: American Medical Society for Sports Medicine position statement: concussion in sport. Br J Sports Med 47:15-26, 2013

47. Herx LM, Rivest S, Yong VW: Central nervous systeminitiated inflammation and neurotrophism in trauma: IL-1 $\beta$ is required for the production of ciliary neurotrophic factor. J Immunol 165:2232-2239, 2000
48. Holmin S, Schalling M, Höjeberg B, Nordqvist AC, Skeftruna AK, Mathiesen T: Delayed cytokine expression in rat brain following experimental contusion. J Neurosurg 86:493-504, 1997

49. Holmin S, Söderlund J, Biberfeld P, Mathiesen T: Intracerebral inflammation after human brain contusion. Neurosurgery 42:291-299, 1998

50. Hootman JM, Dick R, Agel J: Epidemiology of collegiate injuries for 15 sports: summary and recommendations for injury prevention initiatives. J Athl Train 42:311-319, 2007

51. Iverson GL, Gardner AJ, McCrory P, Zafonte R, Castellani RJ: A critical review of chronic traumatic encephalopathy. Neurosci Biobehav Rev 56:276-293, 2015

52. Jagoda AS, Bazarian JJ, Bruns JJ Jr, Cantrill SV, Gean AD, Howard PK, et al: Clinical policy: neuroimaging and decisionmaking in adult mild traumatic brain injury in the acute setting. Ann Emerg Med 52:714-748, 2008

53. Johnson B, Zhang K, Gay M, Horovitz S, Hallett M, Sebastianelli W, et al: Alteration of brain default network in subacute phase of injury in concussed individuals: restingstate fMRI study. Neuroimage 59:511-518, 2012

54. Johnson B, Zhang K, Gay M, Neuberger T, Horovitz S, Hallett M, et al: Metabolic alterations in corpus callosum may compromise brain functional connectivity in MTBI patients: an ${ }^{1} \mathrm{H}-\mathrm{MRS}$ study. Neurosci Lett 509:5-8, 2012

55. Kakuda T: Neuroprotective effects of the green tea components theanine and catechins. Biol Pharm Bull 25:15131518,2002

56. Kakuda T: Neuroprotective effects of theanine and its preventive effects on cognitive dysfunction. Pharmacol Res 64:162-168, 2011

57. Kalimo H, Rehncrona S, Söderfeldt B: The role of lactic acidosis in the ischemic nerve cell injury. Acta Neuropathol Suppl 7:20-22,1981

58. Karantzoulis S, Randolph C: Modern chronic traumatic encephalopathy in retired athletes: what is the evidence? Neuropsychol Rev 23:350-360, 2013

59. Katayama Y, Becker DP, Tamura T, Hovda DA: Massive increases in extracellular potassium and the indiscriminate release of glutamate following concussive brain injury. J Neurosurg 73:889-900, 1990

60. Killam C, Cautin RL, Santucci AC: Assessing the enduring residual neuropsychological effects of head trauma in college athletes who participate in contact sports. Arch Clin Neuropsychol 20:599-611, 2005

61. King D, Hume P, Gissane C, Clark T: Use of the KingDevick test for sideline concussion screening in junior rugby league. J Neurol Sci 357:75-79, 2015

62. Kissick J, Johnston KM: Return to play after concussion: principles and practice. Clin J Sport Med 15:426-431, 2005

63. Kontos AP, Covassin T, Elbin RJ, Parker T: Depression and neurocognitive performance after concussion among male and female high school and collegiate athletes. Arch Phys Med Rehabil 93:1751-1756, 2012

64. Kossmann T, Hans V, Imhof HG, Trentz O, MorgantiKossmann MC: Interleukin-6 released in human cerebrospinal fluid following traumatic brain injury may trigger nerve growth factor production in astrocytes. Brain Res 713:143-152, 1996

65. Langlois JA, Rutland-Brown W, Wald MM: The epidemiology and impact of traumatic brain injury: a brief overview. J Head Trauma Rehabil 21:375-378, 2006

66. Lardner AL: Neurobiological effects of the green tea constituent theanine and its potential role in the treatment of psychiatric and neurodegenerative disorders. Nutr Neurosci 17:145-155, 2014

67. Len TK, Neary JP: Cerebrovascular pathophysiology fol- 
lowing mild traumatic brain injury. Clin Physiol Funct Imaging 31:85-93, 2011

68. Levin HS, Diaz-Arrastia RR: Diagnosis, prognosis, and clinical management of mild traumatic brain injury. Lancet Neurol 14:506-517, 2015

69. Ley EJ, Clond MA, Singer MB, Shouhed D, Salim A: IL6 deficiency affects function after traumatic brain injury. J Surg Res 170:253-256, 2011

70. Lincoln AE, Hinton RY, Almquist JL, Lager SL, Dick RW: Head, face, and eye injuries in scholastic and collegiate lacrosse: a 4-year prospective study. Am J Sports Med 35:207-215, 2007

71. Ling H, Hardy J, Zetterberg H: Neurological consequences of traumatic brain injuries in sports. Mol Cell Neurosci 66 (Pt B):114-122, 2015

72. Lipton ML, Gulko E, Zimmerman ME, Friedman BW, Kim M, Gellella E, et al: Diffusion-tensor imaging implicates prefrontal axonal injury in executive function impairment following very mild traumatic brain injury. Radiology 252:816-824, 2009

73. Lishman WA: Physiogenesis and psychogenesis in the 'post-concussional syndrome'. Br J Psychiatry 153:460469,1988

74. Longhi L, Saatman KE, Fujimoto S, Raghupathi R, Meaney DF, Davis J, et al: Temporal window of vulnerability to repetitive experimental concussive brain injury. Neurosurgery 56:364-374, 2005

75. Lovell MR, Collins MW: Neuropsychological assessment of the college football player. J Head Trauma Rehabil 13:9-26, 1998

76. Maas AI, Murray G, Henney H III, Kassem N, Legrand V, Mangelus M, et al: Efficacy and safety of dexanabinol in severe traumatic brain injury: results of a phase III randomised, placebo-controlled, clinical trial. Lancet Neurol 5:38-45, 2006

77. Maddocks DL, Dicker GD, Saling MM: The assessment of orientation following concussion in athletes. Clin J Sport Med 5:32-35, 1995

78. Majerske CW, Mihalik JP, Ren D, Collins MW, Reddy CC, Lovell MR, et al: Concussion in sports: postconcussive activity levels, symptoms, and neurocognitive performance. J Athl Train 43:265-274, 2008

79. Makdissi M, Darby D, Maruff P, Ugoni A, Brukner P, McCrory PR: Natural history of concussion in sport: markers of severity and implications for management. Am J Sports Med 38:464-471, 2010

80. Mandel SA, Amit T, Weinreb O, Youdim MB: Understanding the broad-spectrum neuroprotective action profile of green tea polyphenols in aging and neurodegenerative diseases. J Alzheimers Dis 25:187-208, 2011

81. Mansell JL, Tierney RT, Higgins M, McDevitt J, Toone N, Glutting J: Concussive signs and symptoms following head impacts in collegiate athletes. Brain Inj 24:1070-1074, 2010

82. Marar M, Mcllvain NM, Fields SK, Comstock RD: Epidemiology of concussions among United States high school athletes in 20 sports. Am J Sports Med 40:747-755, 2012

83. Maroon JC, Lovell MR, Norwig J, Podell K, Powell JW, Hartl R: Cerebral concussion in athletes: evaluation and neuropsychological testing. Neurosurgery 47:659-672, 2000

84. Martland HS: Punch drunk. J Am Med Assoc 91:11031107,1928

85. Maxwell WL, Povlishock JT, Graham DL: A mechanistic analysis of nondisruptive axonal injury: a review. J Neurotrauma 14:419-440, 1997

86. May KH, Marshall DL, Burns TG, Popoli DM, Polikandriotis JA: Pediatric sports specific return to play guidelines following concussion. Int J Sports Phys Ther 9:242-255, 2014

87. McAllister TW, Flashman LA, Maerlender A, Greenwald RM, Beckwith JG, Tosteson TD, et al: Cognitive effects of one season of head impacts in a cohort of collegiate contact sport athletes. Neurology 78:1777-1784, 2012

88. McAllister TW, Flashman LA, McDonald BC, Ferrell RB, Tosteson TD, Yanofsky NN, et al: Dopaminergic challenge with bromocriptine one month after mild traumatic brain injury: altered working memory and BOLD response. J Neuropsychiatry Clin Neurosci 23:277-286, 2011

89. McClain R: Concussion and trauma in young athletes: prevention, treatment, and return-to-play. Prim Care 42:7783,2015

90. McCrea M, Barr WB, Guskiewicz K, Randolph C, Marshall SW, Cantu R, et al: Standard regression-based methods for measuring recovery after sport-related concussion. J Int Neuropsychol Soc 11:58-69, 2005

91. McCrea M, Guskiewicz KM, Marshall SW, Barr W, Randolph C, Cantu RC, et al: Acute effects and recovery time following concussion in collegiate football players: the NCAA Concussion Study. JAMA 290:2556-2563, 2003

92. McCrea M, Kelly JP, Kluge J, Ackley B, Randolph C: Standardized assessment of concussion in football players. Neurology 48:586-588, 1997

93. McCrory P: Does second impact syndrome exist? Clin J Sport Med 11:144-149, 2001

94. McCrory P: When to retire after concussion? Br J Sports Med 35:380-382, 2001

95. McCrory P, Meeuwisse WH, Aubry M, Cantu B, Dvořák J, Echemendia RJ, et al: Consensus statement on concussion in sport: the 4th International Conference on Concussion in Sport held in Zurich, November 2012. J Am Coll Surg 216:e55-e71, 2013

96. McCrory PR, Berkovic SF: Second impact syndrome. Neurology 50:677-683, 1998

97. McKee AC, Cantu RC, Nowinski CJ, Hedley-Whyte ET, Gavett BE, Budson AE, et al: Chronic traumatic encephalopathy in athletes: progressive tauopathy after repetitive head injury. J Neuropathol Exp Neurol 68:709-735, 2009

98. McKee AC, Daneshvar DH, Alvarez VE, Stein TD: The neuropathology of sport. Acta Neuropathol 127:29-51, 2014

99. McKee AC, Gavett BE, Stern RA, Nowinski CJ, Cantu $\mathrm{RC}$, Kowall NW, et al: TDP-43 proteinopathy and motor neuron disease in chronic traumatic encephalopathy. $\mathbf{J}$ Neuropathol Exp Neurol 69:918-929, 2010

100. McKee AC, Stern RA, Nowinski CJ, Stein TD, Alvarez VE, Daneshvar DH, et al: The spectrum of disease in chronic traumatic encephalopathy. Brain 136:43-64, 2013

101. Meehan WP III, d'Hemecourt P, Comstock RD: High school concussions in the 2008-2009 academic year: mechanism, symptoms, and management. Am J Sports Med 38:2405-2409, 2010

102. Metting Z, Wilczak N, Rodiger LA, Schaaf JM, van der Naalt J: GFAP and S100B in the acute phase of mild traumatic brain injury. Neurology 78:1428-1433, 2012

103. Miller JR, Adamson GJ, Pink MM, Sweet JC: Comparison of preseason, midseason, and postseason neurocognitive scores in uninjured collegiate football players. Am J Sports Med 35:1284-1288, 2007

104. Mittl RL, Grossman RI, Hiehle JF, Hurst RW, Kauder DR, Gennarelli TA, et al: Prevalence of MR evidence of diffuse axonal injury in patients with mild head injury and normal head CT findings. AJNR Am J Neuroradiol 15:15831589, 1994

105. Montenigro PH, Baugh CM, Daneshvar DH, Mez J, Budson $\mathrm{AE}, \mathrm{Au} \mathrm{R}$, et al: Clinical subtypes of chronic traumatic encephalopathy: literature review and proposed research 
diagnostic criteria for traumatic encephalopathy syndrome. Alzheimers Res Ther 6:68, 2014

106. Morgan CD, Zuckerman SL, Lee YM, King L, Beaird S, Sills AK, et al: Predictors of postconcussion syndrome after sports-related concussion in young athletes: a matched casecontrol study. J Neurosurg Pediatr 15:589-598, 2015

107. Narayana PA, Yu X, Hasan KM, Wilde EA, Levin HS, Hunter JV, et al: Multi-modal MRI of mild traumatic brain injury. Neuroimage Clin 7:87-97, 2015

108. Niogi SN, Mukherjee P: Diffusion tensor imaging of mild traumatic brain injury. J Head Trauma Rehabil 25:241255,2010

109. Olsson KA, Lloyd OT, Lebrocque RM, McKinlay L, Anderson VA, Kenardy JA: Predictors of child post-concussion symptoms at 6 and 18 months following mild traumatic brain injury. Brain Inj 27:145-157, 2013

110. Omalu B: Chronic traumatic encephalopathy. Prog Neurol Surg 28:38-49, 2014

111. Omalu B, Bailes J, Hamilton RL, Kamboh MI, Hammers $\mathrm{J}$, Case M, et al: Emerging histomorphologic phenotypes of chronic traumatic encephalopathy in American athletes. Neurosurgery 69:173-183, 2011

112. Omalu BI, Bailes J, Hammers JL, Fitzsimmons RP: Chronic traumatic encephalopathy, suicides and parasuicides in professional American athletes: the role of the forensic pathologist. Am J Forensic Med Pathol 31:130-132, 2010

113. Omalu BI, DeKosky ST, Hamilton RL, Minster RL, Kamboh MI, Shakir AM, et al: Chronic traumatic encephalopathy in a National Football League player: part II. Neurosurgery 59:1086-1093, 2006

114. Omalu BI, DeKosky ST, Minster RL, Kamboh MI, Hamilton RL, Wecht CH: Chronic traumatic encephalopathy in a National Football League player. Neurosurgery 57:128-134, 2005

115. Parker HL: Traumatic encephalopathy ('punch drunk') of professional pugilists. J Neurol Psychopathol 15:20-28, 1934

116. Patterson ZR, Holahan MR: Understanding the neuroinflammatory response following concussion to develop treatment strategies. Front Cell Neurosci 6:58, 2012

117. Peloso PM, Carroll LJ, Cassidy JD, Borg J, von Holst H, Holm L, et al: Critical evaluation of the existing guidelines on mild traumatic brain injury. J Rehabil Med 43 Suppl:106-112, 2004

118. Petraglia AL, Maroon JC, Bailes JE: From the field of play to the field of combat: a review of the pharmacological management of concussion. Neurosurgery 70:1520-1533, 2012

119. Petraglia AL, Winkler EA, Bailes JE: Stuck at the bench: Potential natural neuroprotective compounds for concussion. Surg Neurol Int 2:146, 2011

120. Powell JW, Barber-Foss KD: Traumatic brain injury in high school athletes. JAMA 282:958-963, 1999

121. Prabhu SP: The role of neuroimaging in sport-related concussion. Clin Sports Med 30:103-114, ix, 2011

122. Pulsipher DT, Campbell RA, Thoma R, King JH: A critical review of neuroimaging applications in sports concussion. Curr Sports Med Rep 10:14-20, 2011

123. Quintana A, Molinero A, Borup R, Nielsen FC, Campbell IL, Penkowa M, et al: Effect of astrocyte-targeted production of IL-6 on traumatic brain injury and its impact on the cortical transcriptome. Dev Neurobiol 68:195-208, 2008

124. Randolph C: Is chronic traumatic encephalopathy a real disease? Curr Sports Med Rep 13:33-37, 2014

125. Randolph C, Karantzoulis S, Guskiewicz K: Prevalence and characterization of mild cognitive impairment in retired national football league players. J Int Neuropsychol Soc 19:873-880, 2013

126. Randolph C, Millis S, Barr WB, McCrea M, Guskiewicz
KM, Hammeke TA, et al: Concussion symptom inventory: an empirically derived scale for monitoring resolution of symptoms following sport-related concussion. Arch Clin Neuropsychol 24:219-229, 2009

127. Rezai-Zadeh K, Arendash GW, Hou H, Fernandez F, Jensen M, Runfeldt M, et al: Green tea epigallocatechin-3-gallate (EGCG) reduces $\beta$-amyloid mediated cognitive impairment and modulates tau pathology in Alzheimer transgenic mice. Brain Res 1214: 177-187, 2008

128. Riemann BL, Guskiewicz KM: Effects of mild head injury on postural stability as measured through clinical balance testing. J Athl Train 35: 19-25, 2000

129. Schulz MR, Marshall SW, Mueller FO, Yang J, Weaver NL, Kalsbeek WD, et al: Incidence and risk factors for concussion in high school athletes, North Carolina, 1996-1999. Am J Epidemiol 160:937-944, 2004

130. Seidman DH, Burlingame J, Yousif LR, Donahue XP, Krier J, Rayes LJ, et al: Evaluation of the King-Devick test as a concussion screening tool in high school football players. J Neurol Sci 356:97-101, 2015

131. Shenton ME, Hamoda HM, Schneiderman JS, Bouix S, Pasternak O, Rathi Y, et al: A review of magnetic resonance imaging and diffusion tensor imaging findings in mild traumatic brain injury. Brain Imaging Behav 6:137-192, 2012

132. Shiozaki T, Hayakata T, Tasaki O, Hosotubo H, Fuijita K, Mouri T, et al: Cerebrospinal fluid concentrations of antiinflammatory mediators in early-phase severe traumatic brain injury. Shock 23:406-410, 2005

133. Shrey DW, Griesbach GS, Giza CC: The pathophysiology of concussions in youth. Phys Med Rehabil Clin N Am 22:577-602, vii, 2011

134. Slobounov S, Slobounov E, Sebastianelli W, Cao C, Newell $\mathrm{K}$ : Differential rate of recovery in athletes after first and second concussion episodes. Neurosurgery 61:338-344, 2007

135. Smith DW, Bailes JE, Fisher JA, Robles J, Turner RC, Mills JD: Internal jugular vein compression mitigates traumatic axonal injury in a rat model by reducing the intracranial slosh effect. Neurosurgery 70:740-746, 2012

136. Stein TD, Alvarez VE, McKee AC: Chronic traumatic encephalopathy: a spectrum of neuropathological changes following repetitive brain trauma in athletes and military personnel. Alzheimers Res Ther 6:4, 2014

137. Stern RA, Daneshvar DH, Baugh CM, Seichepine DR, Montenigro PH, Riley DO, et al: Clinical presentation of chronic traumatic encephalopathy. Neurology 81:11221129,2013

138. Stern RA, Riley DO, Daneshvar DH, Nowinski CJ, Cantu $\mathrm{RC}$, McKee AC: Long-term consequences of repetitive brain trauma: chronic traumatic encephalopathy. PM R 3 (10 Suppl 2):S460-S467, 2011

139. Sullivan PG, Bruce-Keller AJ, Rabchevsky AG, Christakos S, Clair DK, Mattson MP, et al: Exacerbation of damage and altered NF- $\mathrm{KB}$ activation in mice lacking tumor necrosis factor receptors after traumatic brain injury. J Neurosci 19:6248-6256, 1999

140. Sullivan SJ, Bourne L, Choie S, Eastwood B, Isbister S, McCrory P, et al: Understanding of sport concussion by the parents of young rugby players: a pilot study. Clin J Sport Med 19:228-230, 2009

141. Sweeney TE, Salles A, Harris OA, Spain DA, Staudenmayer KL: Prediction of neurosurgical intervention after mild traumatic brain injury using the national trauma data bank. World J Emerg Surg 10:23, 2015

142. Talavage TM, Nauman EA, Breedlove EL, Yoruk U, Dye $\mathrm{AE}$, Morigaki KE, et al: Functionally-detected cognitive impairment in high school football players without clinically-diagnosed concussion. J Neurotrauma 31:327-338, 2014 
143. Vagnozzi R, Signoretti S, Cristofori L, Alessandrini F, Floris R, Isgrò E, et al: Assessment of metabolic brain damage and recovery following mild traumatic brain injury: a multicentre, proton magnetic resonance spectroscopic study in concussed patients. Brain 133:3232-3242, 2010 (Erratum in Brain 136:11, 2013)

144. Vagnozzi R, Signoretti S, Tavazzi B, Floris R, Ludovici A, Marziali S, et al: Temporal window of metabolic brain vulnerability to concussion: a pilot ${ }^{1} \mathrm{H}$-magnetic resonance spectroscopic study in concussed athletes-part III. Neurosurgery 62:1286-1296, 2008

145. Vagnozzi R, Tavazzi B, Signoretti S, Amorini AM, Belli A, Cimatti M, et al: Temporal window of metabolic brain vulnerability to concussions: mitochondrial-related impairment - part I. Neurosurgery 61:379-389, 2007

146. Ventura RE, Balcer LJ, Galetta SL: The concussion toolbox: the role of vision in the assessment of concussion. Semin Neurol 35:599-606, 2015

147. Washington CW, Grubb RL Jr: Are routine repeat imaging and intensive care unit admission necessary in mild traumatic brain injury? J Neurosurg 116:549-557, 2012

148. Williams DH, Levin HS, Eisenberg HM: Mild head injury classification. Neurosurgery 27:422-428, 1990

149. Xiong Y, Gu Q, Peterson PL, Muizelaar JP, Lee CP: Mitochondrial dysfunction and calcium perturbation induced by traumatic brain injury. J Neurotrauma 14:23-34, 1997

150. Yoshino A, Hovda DA, Kawamata T, Katayama Y, Becker DP: Dynamic changes in local cerebral glucose utilization following cerebral conclusion in rats: evidence of a hyperand subsequent hypometabolic state. Brain Res 561:106119,1991

151. Yu CH, Yhee JY, Kim JH, Im KS, Kim NH, Jung DI, et al Pro- and anti-inflammatory cytokine expression and histopathological characteristics in canine brain with traumatic brain injury. J Vet Sci 12:299-301, 2011

152. Zhang K, Johnson B, Pennell D, Ray W, Sebastianelli W,
Slobounov S: Are functional deficits in concussed individuals consistent with white matter structural alterations: combined FMRI \& DTI study. Exp Brain Res 204:57-70, 2010

153. Zhang L, Yang KH, King AI: A proposed injury threshold for mild traumatic brain injury. J Biomech Eng 126:226236, 2004

154. Ziebell JM, Morganti-Kossmann MC: Involvement of pro- and anti-inflammatory cytokines and chemokines in the pathophysiology of traumatic brain injury. Neurotherapeutics 7:22-30, 2010

155. Žurek J, Fedora M: The usefulness of S100B, NSE, GFAP, $\mathrm{NF}-\mathrm{H}$, secretagogin and Hsp70 as a predictive biomarker of outcome in children with traumatic brain injury. Acta Neurochir (Wien) 154:93-103, 2012

\section{Disclosures}

The authors report no conflict of interest concerning the materials or methods used in this study or the findings specified in this paper.

\section{Author Contributions}

Conception and design: all authors. Acquisition of data: all authors. Drafting the article: all authors. Critically revising the article: all authors. Reviewed submitted version of manuscript: all authors. Approved the final version of the manuscript on behalf of all authors: Hobbs. Administrative/technical/material support: all authors.

\section{Correspondence}

Jonathan G. Hobbs, Department of Surgery, Section of Neurosurgery, University of Chicago, MC 3026, J341, 5841 S. Maryland Ave., Chicago, IL 60637. email: jonathan.hobbs@uchospitals. edu. 